\title{
Impact of russian and foreign students' personal characteristics on learning outcomes
}

\author{
Fisochenko Oksana ${ }^{1}$, Berestneva Elena ${ }^{2}$, Marukhina \\ $\mathrm{Olga}^{2}$, Romanchukov Sergey ${ }^{2}$ \\ ${ }^{1}$ Yurginsky institute of technology, ${ }^{2}$ Institute of \\ Cybernetics \\ ${ }^{1,2}$ National Research Tomsk Polytechnic University \\ Tomsk, Russia \\ giri@rambler.ru
}

\author{
Petrova Ludmila \\ State University of Humanities and Technology \\ Orekhovo-Zuyevo, Russia \\ petrova_ludmila@mail.ru
}

\begin{abstract}
The article is devoted to studying interpersonal characteristics of Russian and foreign students training in the specialty of «Linguistics» and the impact of these characteristics on students' performance results. The methods «subjective control level», "type of thinking», «tendency to victim behavior» were chosen for the study. The interrelation of personality characteristics of foreign and Russian linguistics students and their learning outcomes were identified with the help of correlation analysis. The analysis showed that demonstration of externality by foreign students has a direct impact on their performance results. The higher level of Russian language foreign students have, the easier it is for them to develop their skills and show high performance while training in the subjects related to their professional sphere. The influence of type of thinking and country of residence on the indicators of subjective control and performance of foreign and Russian students were estimated by the method of variance analysis. It was revealed that type of thinking does not affect the basic investigated parameters, but the country of residence has a direct impact on the student's internality and learning activity in general and vocational subjects apart from the subject «Physical education».
\end{abstract}

Keywords-personal characteristics; data analysis; performance; correlation analysis; variance analysis.

\section{INTRODUCTION}

In modern world high level of international activity and cooperation is vital for universities and their successful development. This problem is quite important and a lot of researches have been conducted in this sphere by the scientists of different countries of the world during the last few years $[1,2]$. Teaching foreign students with respect to their culture and unique traditions is one of the important aspects of the university's international activity [3]. The process of social and psychological adaptation while moving to another culture is seen as a series of stressful changes that requires individual adaptive resources of mobilization and obligatory response. Successful adaptation of an individual is characterized by positive emotional state and acquisition of social skills and knowledge, which allows students to successfully perform routine tasks in their new cultural environment [4].
The need to adapt to new surroundings becomes challenging for individual choice and implementation of appropriate adaptation strategies. The way the personal human potential is included in the adaptation process will finally determine the success of all adaptation process [5].

Personal creativity during adaptation creates opportunities for performing vital tasks of optimal functioning, developing skills of effective recovery, striving to reveal the full potential of foreign students. The process of adaptation is a challenge for personal growth because it involves breaking the life stereotypes and requires personal resources. Another view of their rules and habits can help to notice personal characteristics, to compare and evaluate the differences and to understand themselves and the others better, which makes the problems of intercultural communication much easier to solve [6].

Ensuring a tolerant educational environment becomes relevant during the formation of the international educational space and the growth of academic mobility $[7,8]$. The solution to this problem is to provide support for international students during their adaptation to a new culture and the university educational space.

Successful adaptation facilitates the rapid entry of foreign and Russian students into the learning process and affects the quality of their training [9].

\section{OBJECTIVES, METHODOLOGY AND RESEARCH DESIGN}

The high anxiety level of the first-year foreign students of Tomsk Polytechnic University (TPU) determines the relevance of a regular study of students' adaptation and the need to enhance adaptation programs for students as well as development of the university staff professional competencies[10-12]. It is necessary to know about the personal features of Russian and foreign students in order to have an opportunity to organize the educational process efficiently, which will result in higher students' performance and successful adaptation.

The purpose of this study was to examine the interpersonal characteristics of Russian and foreign linguistics students and 
identify the impact of these characteristics on their learning outcomes.

The main objectives of the study are as follows:

1) To conduct a comparative analysis of monitored data concerning Russian and foreign first-year students of Linguistics.

2) To identify the interconnection of personality characteristics of Russian and foreign students of Linguistics and their learning outcomes using the methods of correlation analysis.

3) To apply the method of variance analysis for assessing the influence of type of thinking and the country of residence on the indicators of subjective control and performance of foreign and Russian students.

The research is done in 2014-2015. At the preliminary stage 64 first-year students of TPU training in the specialty of «Linguistics» were tested. The experimental data are the test results for the three methods («subjective control level», «type of thinking» and «tendency to victim behavior»), as well as the results of the checkpoints (scores) in two general and three specific disciplines.

\section{RESULTS AND DISCUSSION.}

A. Comparative analysis of monitored data concerning Russian and foreign first-year students of Linguistics

At the first stage test results showed the percentage of foreign and Russian students training in the specialty of «Linguistics» belonging to internality and externality types according to the subjective control scaling method.

Assessing the level of subjective control was carried out on the following scales:

- $\quad \boldsymbol{t} \boldsymbol{t}$ - scale of total internality.

- $\quad \boldsymbol{I} \boldsymbol{a}$ - scale of internality in the achievements.

- $\quad \boldsymbol{f} \boldsymbol{f}$ - scale of internality in failure.

- Ifr-scale of internality in family relations.

- $\quad \boldsymbol{I} \boldsymbol{p}$ - scale of internality in professional relations.

- $\quad \boldsymbol{I} \boldsymbol{i}$ - scale of internality in interpersonal relations.

- $\quad \boldsymbol{I} \boldsymbol{h}$ - scale of internality in health and disease.

«Level of subjective control» method is a modified version of the questionnaire created by American psychologist John Rotter [12]. It can be used to assess the level of subjective control over a variety of situations, or, in other words, to determine the degree of students' responsibility for their actions and their lives. There are two types of polar localization: externality (external locus of control) and internality (internal locus of control). Students with external locus of control tend to have comfortable and compliant behavior. They are quite passive, anxious, and dependent, and prefer teamwork. Students with internal locus of control demonstrate a positive self-esteem. They are active, independent, and able to solve various problems on their own .
Summary of the procedure «tendency to victim behavior» was carried out on the following scales:

- $\boldsymbol{r} . \boldsymbol{v}$ - scale of realized victimity.

- $\boldsymbol{a}$ - tendency to aggressive victim behavior.

- $s$ - tendency to self-harm and self-destructive behavior.

- $\boldsymbol{h}$ - tendency to hyper-social victim behavior.

- $\boldsymbol{a} \boldsymbol{h}$ - tendency to addictive and helpless behavior.

- $\boldsymbol{n}$ - tendency to noncritical behavior.

The results of the test analysis of foreign linguistics students from Vietnam indicated that they tend to have externality type of subjective control (Table I).

TABLE I. TABLE 1. LINGUISTICS STUDENTS FROM VIETNAM («SUBJECTIVE CONTROL LEVEL » METHOD)

\begin{tabular}{|l|l|l|l|l|l|l|l|}
\hline \multirow{2}{*}{$\begin{array}{l}\text { Subjective } \\
\text { control levels }\end{array}$} & \multicolumn{7}{|c|}{ The level of subjective control, \% } \\
\cline { 2 - 8 } & It & Ia & If & Ifr & Ip & I & Ih \\
\hline $\begin{array}{l}\text { Internal } \\
(7-9)\end{array}$ & 7,1 & 21,4 & 0,0 & 21,4 & 7,1 & 7,1 & 21,4 \\
\hline $\begin{array}{l}\text { Intermediate } \\
(5-6)\end{array}$ & 21,4 & 28,6 & 0,2 & 35,7 & 21,4 & 35,7 & 14,3 \\
\hline $\begin{array}{l}\text { External } \\
(1-4)\end{array}$ & 71,4 & 50,0 & 78,6 & 42,9 & 71,4 & 57,1 & 64,3 \\
\hline
\end{tabular}

Apparently the cultural traditions of the country affect the level of subjective control. Vietnamese have great respect to their parents and obey them, and therefore they often shift responsibility on parents. Also Vietnamese tend to show a deep respect for the people with high status and rank. Vietnamese students are diligent in study, they listen to their teachers and respect them but often are not inclined to make independent decisions.

If we consider the parameters of each scale we'll see that approximately $70 \%$ of the students show externality in the following scales: It, If, Ip, Ih. These students shift the blame for their failure on the fate and other people in the matters related to health, luck and professional success. Foreign students show the smallest externality on scale If (family relations) $-42.86 \%$.

Russian students test results analysis show that they are more inclined to represent internal type of subjective control (Table II). About 50\% of Russian students showed high levels of externalities on the scale: If; Ip, Ih.

TABLE II. LINGUISTS STUDENTS FROM RUSSIA («SUBJECTIVE CONTROL LEVEL» METHOD)

\begin{tabular}{|l|c|c|c|c|c|c|c|}
\hline \multirow{2}{*}{$\begin{array}{l}\text { Subjective } \\
\text { control levels }\end{array}$} & \multicolumn{7}{|c|}{ The level of subjective control, \% } \\
\cline { 2 - 8 } & It & Ia & If & Ifr & Ip & I & Ih \\
\hline $\begin{array}{l}\text { Internal } \\
(7-9)\end{array}$ & 25,7 & 37,1 & 22,8 & 45,7 & 14,3 & 25,7 & 28,6 \\
\hline $\begin{array}{l}\text { Intermediate } \\
(5-6)\end{array}$ & 37,1 & 45,7 & 22,8 & 42,9 & 34,3 & 33,4 & 20,3 \\
\hline $\begin{array}{l}\text { External } \\
(1-4)\end{array}$ & 37,1 & 17,1 & 54,3 & 11,4 & 51,4 & 40,9 & 48,3 \\
\hline
\end{tabular}


Test analysis results of the "type of thinking" evaluation method showed that foreign linguistics students tend to show analytical type of thinking (36\%) and, to a slightly lesser degree, - idealistic type of thinking (29\%) (Fig. 1).

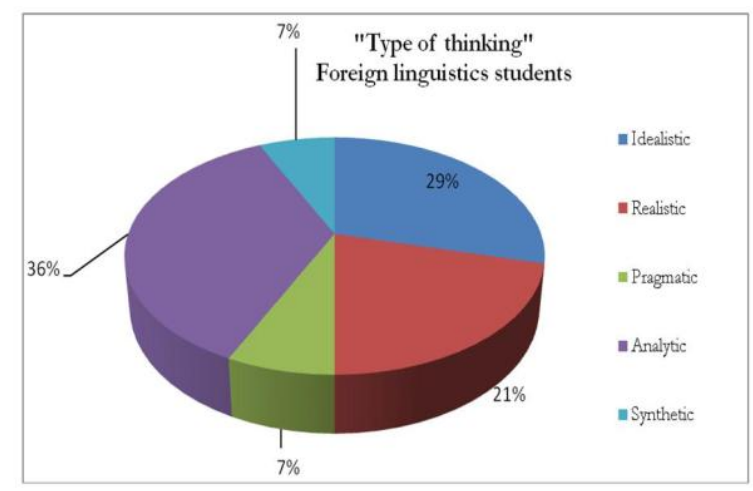

Fig. 1. Diagram of foreign linguistics students distribution by the type of thinking

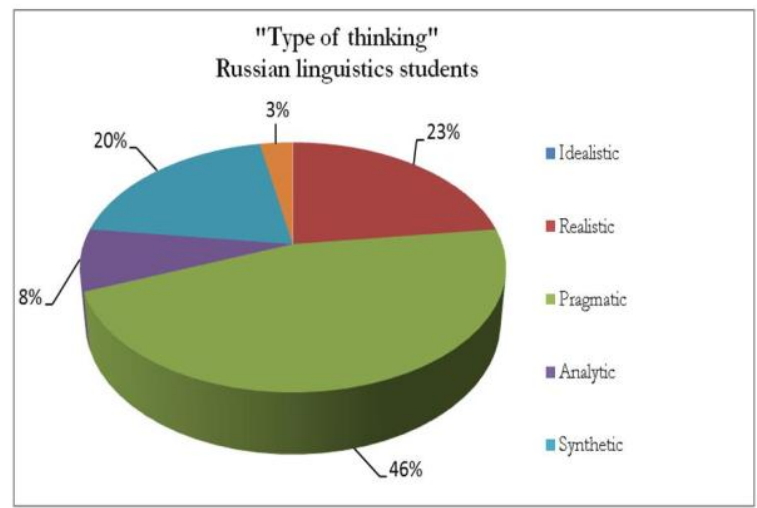

Fig. 2. Diagram of russian linguistics students distribution by the type of thinking

Russian linguistics students are more inclined to represent realistic type of thinking (45\%) (Fig. 2).

Analysis of the «victim behavior tendency» method showed that students from Vietnam display a high percentage of victim tendencies in the studied scales (Table III). Table IV shows the results of Russian students.

TABLE III. LINGUISTICS STUDENTS FROM VIETNAM ( «VICTIM BEHAVIOR TENDENCY» METHOD)

\begin{tabular}{|c|l|l|l|l|l|l|}
\hline & \multicolumn{6}{|c|}{ Victim behavior tendency, \% } \\
\cline { 2 - 7 } & $\boldsymbol{r} . \boldsymbol{v} \cdot$ & $\boldsymbol{a}$ & $\boldsymbol{s}$ & $\boldsymbol{h}$ & $\boldsymbol{a h}$ & $\boldsymbol{n}$ \\
\hline $\begin{array}{c}\text { Above normal } \\
(8-10)\end{array}$ & 17 & 68,6 & 65,7 & 8,6 & 17,1 & 85,7 \\
\hline $\begin{array}{c}\text { Normal } \\
(4-7)\end{array}$ & 65,7 & 31,4 & 31,4 & 77,1 & 74,3 & 14,3 \\
\hline $\begin{array}{c}\text { Below normal } \\
(1-3)\end{array}$ & 17,1 & 0,0 & 2,9 & 14,3 & 8,6 & 0,0 \\
\hline
\end{tabular}

TABLE IV. RUSSIAN LINGUISTICS STUDENTS («VICTIM BEHAVIOR TENDENCY» METHOD)

\begin{tabular}{|c|c|c|c|c|c|c|}
\hline \multirow{2}{*}{} & \multicolumn{6}{|c|}{ Victim behavior tendency, \% } \\
\cline { 2 - 7 } & $\boldsymbol{r . v .}$ & $\boldsymbol{a}$ & $\boldsymbol{s}$ & $\boldsymbol{h}$ & $\boldsymbol{a h}$ & $\boldsymbol{n}$ \\
\hline $\begin{array}{c}\text { Above } \\
\text { normal } \\
(8-10)\end{array}$ & 42,8 & 71,4 & 85,7 & 35,7 & 71,4 & 57,1 \\
\hline $\begin{array}{c}\text { Normal } \\
(4-7)\end{array}$ & 57,1 & 28,6 & 14,3 & 64,3 & 28,6 & 42,8 \\
\hline $\begin{array}{c}\text { Below } \\
\text { normal } \\
(1-3)\end{array}$ & 0,0 & 0,0 & 0,0 & 0,0 & 0,0 & 0,0 \\
\hline
\end{tabular}

A high percentage of of victimity in terms of «tendency to aggressive victim behavior» and «tendency to self-harm and self-destructive behavior» appears in both groups, perhaps it is related to the age of the students. They are young and assert themselves at that age, so they can be aggressive and not always able to control their emotions.

The indicator «h - a tendency to hyper-social victim behavior» is normal in both groups, which suggests that these students are quite tolerant and have a normal self-esteem.

The high rate of «n - a tendency to noncritical behavior» indicator shows the inability to evaluate life situations properly and it is presented by $85.71 \%$ of foreign students and $57.14 \%$ of Russian students.

The high rate of «ah» indicated by $71.43 \%$ of students from Vietnam suggests that these students tend to be dependent and helpless, which was also confirmed by the test results of «subjective control level » method, which showed that these students tend to have an external locus of control. High percentage of victimity among Vietnamese students can indicate a hidden aggression or stress that they experienced in that situation, in spite of the external kindness.

B. Evaluation of the interconnection between foreign and Russian linguistics students' personality characteristics and their learning outcomes.

Spearman's correlation coefficient was applied to evaluate interrelation of students' personality characteristics and their perfomance. For this analysis the students' marks in two general and three special subjects were used. There was also evaluated the interconnection of personality characteristics measured by the "subjective control level" and "tendency to victim behavior" testing procedures.

Foreign students show a direct connection between the indicators such as «It» и «Ia », «Ifr», «Ip», «Ii », «Ih»; «Ia» и $\langle\mathrm{It} »,\langle\mathrm{Iff} »,\langle\mathrm{Ip} »,\langle\mathrm{Ii} »,\langle\mathrm{Ih} » ;\langle\langle\mathrm{Ip} »$ и $\langle\mathrm{It} »,\langle\mathrm{Ia} »,\langle\mathrm{Ii} » ;\langle\mathrm{Ii} »$ и «It», «Ia», «I $»\rangle,\langle\mathrm{Ih} » ;$ «Ih » и «It», «Ia», «Ii»».

There can be traced the feedback between the index «It total internality» and «Ii - internality in the area of interpersonal relations» with the figures «s - a tendency to self-harm and self-destructive behavior» and «n - a tendency to noncritical behavior». The more foreign students are responsible for their relationship with people, the more others respect them and feel sympathy to them, and the less they tend to have victim behavior that intentionally causes aggression. 
Almost all «tendency to victim behavior» indicators are closely interrelated, apart from the indicators «h - tendency to hyper-social victim behavior» and «ah - tendency to dependent and helpless behaviors», which are not associated with any of the studied parameters.

Progress in the subject «Introduction to the profession» is directly linked to «It», «Is» and «Ih» performance. Consequently, the higher level of student's responsibility for their health, family and events in their lives causes the higher level of achievement in subjects related to their future professional activity. Indicators of victimity (such as «r.v», «a», «(S», «n») directly affect studying «English».

Index «If» (internality in failure) is not associated with any other test indicator, but has the inversed feedback from learning outcomes in the subject «History». The lower «If» is, the better learning outcomes in this subject are.

Also there is a correlation with disciplines «Introduction to the profession» and «Practical Course 2 - the second foreign language (Russian)» connected with learning Russian language. This relationship suggests that high level of Russian language makes it easier for foreign students to learn and to have high learning outcomes in disciplines related to the main professional activity.

Russian students' indicators show weak interrelation between the level of subjective control and performance indicators for the general and vocational subjects. But within the group, these figures are well correlated.

Russian students have interconnection between the indicators «It» and «Ia », «If », «Ifr», «Ip», «Ii », «Ih» in the group of «subjective control level» method.

The analysis of interrelation between this technique's parameters with the parameters of other methods showed that the level of «internality in health and disease (Ih)» has inverse correlation with the «tendency to aggressive victim behavior (a)» and direct correlation with the «tendency to hyper-social victim behavior (d)». It can be concluded that the more responsibility Russian students have for their health, the less aggressive victim behavior towards others they exhibit and the more evident positive behavior they have in the situations of conflict or intolerance violating public order.

The group of indicators described in «tendency to victim behavior» shows a direct link between performance of «realized victimity» and «tendency to aggressive victim behavior», with «tendency to self-harm and self-destructive behavior» and «tendency to noncritical behavior (n)». We can also see that «tendency to dependent and helpless behavior» is strictly associated with «tendency to hyper-social victim behavior».

C. Assessment of the influence of type of thinking and the country of residence on the indicators of subjective control and performance of foreign and Russian linguistics students

We investigated the influence of factors such as type of thinking and country of residence on the indicators of subjective control and performance of foreign and Russian linguistics students using the methods of variance analysis[13$15]$.

The variance analysis results of the named indicators of victim behavior and subjective control level are presented in Table V.

TABLE V. RESULTS OF FOREIGN AND RUSSIAN STUDENTS' CHARACTERISTICS VARIANCE ANALYSIS (ANOVA)

\begin{tabular}{|l|l|l|l|l|}
\hline \multirow{2}{*}{ variables } & \multicolumn{2}{|c|}{$\begin{array}{c}\text { "Type of thinking" } \\
\text { factor }\end{array}$} & \multicolumn{2}{c|}{ "Country" factor } \\
\cline { 2 - 5 } & $\boldsymbol{F}$ & $\boldsymbol{p}$ & $\boldsymbol{F}$ & \\
\hline It & 0,54 & 0,709 & 8,16 & 0,008 \\
\hline Ia & 0,27 & 0,896 & 3,63 & 0,066 \\
\hline If & 0,62 & 0,654 & 6,62 & 0,015 \\
\hline Ifr & 1,50 & 0,229 & 6,68 & 0,015 \\
\hline Ip & 1,38 & 0,265 & 0,98 & 0,331 \\
\hline Ii & 0,15 & 0,959 & 2,25 & 0,144 \\
\hline Ih & 0,87 & 0,494 & 0,34 & 0,564 \\
\hline r.v. & 1,21 & 0,333 & 4,41 & 0,046 \\
\hline a & 1,31 & 0,292 & 0,40 & 0,531 \\
\hline s & 1,43 & 0,252 & 0,12 & 0,731 \\
\hline h & 0,91 & 0,475 & 11,72 & 0,002 \\
\hline ah & 0,49 & 0,742 & 5,63 & 0,026 \\
\hline n & 0,67 & 0,618 & 4,89 & 0,036 \\
\hline History & 0,48 & 0,748 & 11,59 & 0,002 \\
\hline English & 0,76 & 0,560 & 11,13 & 0,002 \\
\hline $\begin{array}{l}\text { Second Foreign } \\
\text { Language }\end{array}$ & 0,22 & 0,927 & 6,76 & 0,015 \\
\hline Introduction to & 1,51 & 0,226 & 13,62 & 0,001 \\
\hline Physical & 0,69 & 0,608 & 3,90 & 0,058 \\
\hline & & & & \\
\hline
\end{tabular}

Analysis of the ANOVA results showed that «type of thinking» factor has no effect on any indicator and test performance. The factor associated with the country of residence has a direct impact on the «total internality», «internality in the field of failure», «internality in family relations», as well as on progress in all educational and vocational subjects apart from the «Physical education» subject. Also the factor related to the students' country of residence affects the «realized victimity», «tendency to hipersocial victim behavior», "dependence and addictive helpless behavior», «tendency to noncritical behavior» and does not affect the «tendency to aggressive victim behavior» and «tendency to self-harm and self-destructive behavior».

\section{CONCLUSION}

The authors conducted a comparative analysis of monitored data of Russian and foreign first-year linguistics students. The interconnection of their personal characteristics and their learning outcomes was revealed using the methods of correlation analysis. 
Mostly, foreign students showed external type of subjective control. Correlation analysis showed that demonstration of their externality directly affects the results of their performance. Also foreign linguistics students showed that high level of Russian language facilitates learning process and they have high learning outcomes in disciplines related to their professional activity. A high percentage of victimity demonstration in the «tendency to victim behavior» scales among foreign students may indicate underlying aggression or stress that they experience in this situation despite the external kindness.

Russian students generally demonstrated internal type of subjective control. Correlation analysis shows that Russian students' subjective control indicators do not affect their performance. Russian students exposed the realistic type of thinking, internal style of subjective control. Tendency to victim behavior on some scales is little larger than a normal indicator.

The influence level of the type of thinking and country of residence on the subjective control indicators and performance of foreign and Russian linguists students was evaluated by using the methods of variance analysis. It was found that the factor associated with the country of residence affects the performance of students, but does not influence their type of thinking.

The report study was partially supported by the RFBR, research project №14-06-00026.

\section{REFERENCES}

[1] Abe J., Talbot D.M. \& Geelhoed R.J. Effects of a peer program on international student adjustment. Journal of College Student Development, 39, 1998, pp. 539-574.

[2] Lievens F., Harris M., Van Keer E., \& Bisqueret, C. Predicting cross cultural training performance: The validity of personality, cognitive ability, and dimensions measured by an assessment center and a behavior description interview. Journal of Applied Psychology., 88, 2003, pp. 476 - 489.

[3] Barker M., Child C. \& Gallois C. Difficulties of overseas students in social and academic situations. Australian Journal of Psychology, 43 (2), 1991, pp.79-84.

[4] Berestneva O. G. , Marukhina O. V. , Fisochenko O. N. Romanchukov S. V. Information technology assessment of competence of technical university students // 2015 International Siberian Conference on Control and Communications (SIBCON) : proceedings, Omsk, May 21-23, 2015. - Новосибирск: IEEE Russia Siberia Section, 2015, pp. $1-4$

[5] Hannigan T. P. Traits, attitudes, and skills that are related to intercultural effectiveness and their implications for cross - cultural training: A review of the literature. International Journal of Intercultural Relations, 14, 1990, pp. 89 - 111.

[6] Mendenhall M., \& Oddou G. Acculturation profiles of expatriate managers: Implications for cross - cultural training programs. Columbia Journal of World Business, 21, 1986, pp. 73 - 79.

[7] Chebotarjova, E. Ju. Mezhkul'turnaja adaptacija k Rossii studentov iz Azii, Afriki, Latinskoj ameriki i Blizhnego vostoka. [Intercultural adaptation to Russia of students from Asia, Africa, Latin America and the Middle East]. Vestnik Rossijskogo universiteta druzhby narodov. Serija: Psihologija i pedagogika, 3, 2011, pp. 6 - 11.

[8] Dubinina I. A. , Berestneva O. G. , Sviridov K. A. Educational technologies for forming intellectual competence in scientific research and engineering business // Procedia - Social and Behavioral Sciences. 2015, Vol. 166 , pp. $320-324$
[9] Ibadova T.I. The Problem of Tolerance in Modern Foreign Psychology. Bulletin of Peoples' Friendship University of Russia. Series: Psychology and Pedagogics, 3, 2011, pp. 68 - 74

[10] Maroukhina O.V., Berestneva O.G. Expert Support system for Making Dicision by the Results of Computer-Based Testing within the Ends of Teaching Quality Evaluation //Proceedings the 7-th Korea - Russia International Symposium on Science and Technology - Ulsan Republic of Korea, June 28 - Jule 6, 2003. - Ulsan Republic of Korea: University of Ulsan, 2003, pp. 416-419 (73320993)

[11] Maroukhina O.V., Berestneva O.G. Expert Support System for Making Decision by the Results of Computer-Based Testing within the Ends of Teaching Quality Evaluation //Proceedings The 7th Korea-Russia International Symposium on Science and Technology KORUS 2003 Repablic of Korea, June 28-July 6, 2003. - University of Ulsan , 2003, pp. 416-419 (62427518)

[12] Rotter J. B. Social learning and clinical psychology. New York: Prentice - Hall., 1954.

[13] Berestneva O. G. , Volovodenko V. A. , Gerget O. M. , Sharopin K. A. , Osadchaya I. A. Multidimensional Medical Data Visualization Methods Based on Generalized Graphic Images // World Applied Sciences Journal, 2013, №. 24, p. 18-23

[14] Berestneva O. G. , Marukhina O. V. , Benson G. F. , Zharkova O. S. Students' competence assessment methods // Procedia - Social and Behavioral Sciences, 2015, Vol. 166, pp. 296-302

[15] Marukhina O. V., Berestneva O. G., Kozlova N. V. , Lombardo K. S. Modeling coping strategies of technical university students // Communications in Computer and Information Science, 2015, Vol. 535, pp. $81-90$ 